\title{
Recognition of Leukaemia Cells as Foreign before and after Autoimmunization
}

\author{
R. L. POWLES, L. A. BALCHIN, G. HAMILTON FAIRLEY, P. ALEXANDER
}

British Medical fournal, 1971, 1, 486-489

\section{Summary}

Leukaemia cells in the peripheral blood of nine patients with acute leukaemia were removed and stored. When the patients had been brought into haematological remission these leukaemia cells were cultured with autologous lymphocytes both before and after the patients had been autoimmunized with their own irradiated leukaemia cells. The extent to which the leukaemia cells stimulated the "normal lymphocytes" was increased as the result of autoimmunization.

The implications of the use of this test for determining the best regimen for "immunotherapy" in acute leukaemia are discussed.

\section{Introduction}

Leukaemia cells from patients with acute leukaemia have previously been shown to stimulate in vitro DNA synthesis in autologous lymphocytes (Fridman and Kourilsky, 1969; Viza et al., 1969), and our data confirming this are reported here. These experiments suggest that the leukaemia cells carry in their surface an antigen which is either absent or hidden in the lymphocytes of these patients.

We decided to study the changes in the capacity of the patients' lymphocytes to react against their own leukaemia cells in vitro, after autoimmunization. These are of special importance in providing a guide for the use of "immunotherapy" with patients when in haematological remission, a procedure that has been shown to be useful in some experimental tumours (Mathé et al., 1967; Parr, 1971) and possibly in man (Mathé, 1969).

\section{Patients and Methods}

This work was based on the mixed lymphocyte reaction (Bain, 1970) in which two populations of lymphocytes were confronted in tissue culture. The "stimulating lymphocytes" can be considered as the antigen which causes the "reacting lymphocytes" to transform into DNA synthesizing blast cells, the latter being referred to as "transformed cells." To avoid confusion the blast cells present in the peripheral blood of patients with acute leukaemia are referred to as "leukaemia cells." Two types of culture were studied. (1) Both cell populations were from the same patient-that is, leukaemia cells versus lymphocytes-and such cultures are referred to as "autologous mixed cell reactions." (2) The cells used were obtained from two different individuals-that is, the cells are allogeneic with respect to one another-and these reactions are referred to as "allogeneic mixed cell reactions."

Nine patients with acute leukaemia were included in the

Chester Beatty Research Institute, Belmont, Sutton, Surrey

R. L. POWLES, B.SC., M.R.C.P. Research Fellow

L. A. BALCHIN, B.SC., Research Assistant

G. HAMILTON FAIRLEY, D.M., F.R.C.P., Consultant Physician

P. ALEXANDER, D.SC., PH.D., Professor of Radiobiology, study-four with acute myeloblastic leukaemia and five with acute lymphoblastic leukaemia. The term "remission lymphocytes" refers to lymphocytes obtained from the peripheral blood of these patients after intensive chemotherapy when they had no detectable leukaemia cells present in either their blood or bone marrow-that is, they were in complete haematological remission.

DNA synthesis in transformed cells was measured by the incorporation of radioactive thymidine and is expressed in counts per minute per culture. Subsequently seven of these patients were injected with their own killed leukaemia cells, and this is referred to as "autoimmunization."

\section{AUTOLOGOUS MIXED CELL REACTION}

The general outline of the experiment is shown in Fig. 1. It was designed to determine if patients' remission lymphocytes were stimulated in culture by autologous leukaemia cells. The leukaemia cells had been stored in dimethylsulphoxide (DMSO) at $-179^{\circ} \mathrm{C}$ by the method described below. Leukaemia cells were collected from the peripheral blood of patients in the study before any treatment, by using the NCl IBM cell separator in a manner similar to that used to obtain granulocytes from donors for white cell transfusions (Buckner et al., 1969). The number of cells collected was variable and depended on the patients' initial white cell count of the peripheral blood; with $10,000 / \mathrm{mm}^{3}$ the yield was approximately $1 \times 10^{10}$ cells and with $100,000 / \mathrm{mm}^{3}$ it was $5 \times 10^{11}$ cells (equivalent to 200 $\mathrm{ml}$ of packed cells). These leukaemia cells were suspended in acid-citrate dextrose (Fenwal Ltd., formula A) and the patients' own serum. This suspension was mixed with an equal volume of $20 \%$ DMSO in tissue culture medium 199 (Wellcome) and frozen at $1 \%$ minute to $-30^{\circ} \mathrm{C}$ in multiple sterile glass ampoules. These ampoules were stored in liquid nitrogen and when required rapidly thawed at $37^{\circ} \mathrm{C}$, washed

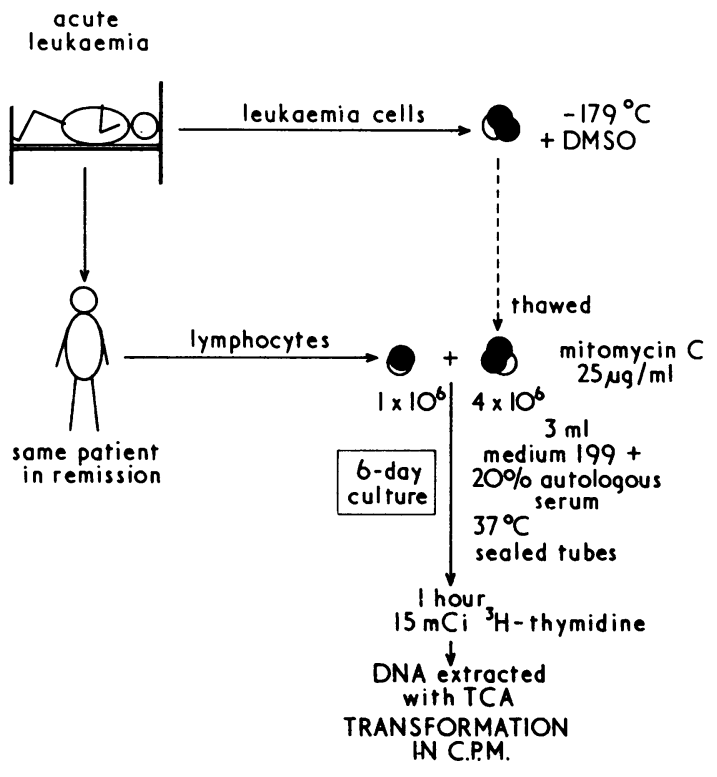

FIG. 1-Summary of experimental procedure. 

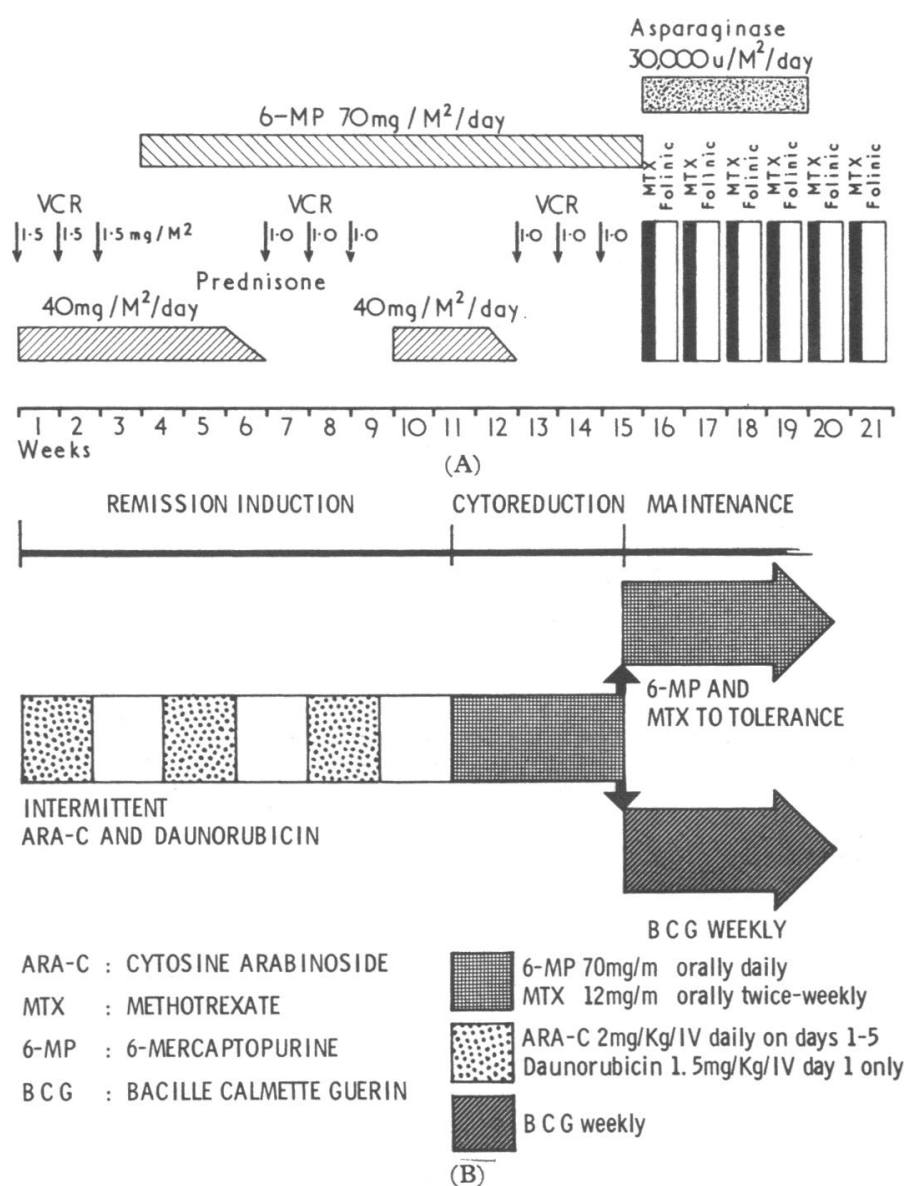

FIG. 2-A, Medical Research Council chemotherapy protocol for patients with acute lymphoblastic leukaemia. B, Chemotherapy protocol for patients with acute lymphoblastic leukaemia. B, Chemotherapy protoc
with acute myeloblastic leukaemia (Crowther et al., 1970).

three times in tissue culture medium 199, and resuspended in this medium at $4^{\circ} \mathrm{C}$. This procedure damaged a fraction of the cells, but in general $70 \%$ of them remained morphologically intact as judged by dye exclusion and phase contrast microscopy. The integrity of these cells was also demonstrated by incorporation of radioactive ${ }^{51} \mathrm{Cr}$ in the form of sodium chromate which could be released after mechanical disruption.

After obtaining the leukaemia cells patients were treated with intensive chemotherapy (Fig. 2), those with acute lymphoblastic leukaemia receiving the Medical Research Council protocol (to be published) and those with acute myeloblastic leukaemia being treated with daunorubicin (rubidomycin) and cystosine arabinoside (Crowther et al., 1970). This study was confined solely to patients who achieved complete haematological remission.

Lymphocytes from the peripheral blood of the patients in remission were cultured with thawed autologous leukaemia cells. Suspensions of the lymphocytes were obtained by removal of red cells and granulocytes from defibrinated blood with the use of methyl cellulose and finely divided carbonyl iron (Coulson and Chalmers, 1967). The supernatants from these suspensions were used as a source of fresh serum and contained methyl cellulose-that is, initially $6 \mathrm{ml}$ of methyl cellulose was added to $20 \mathrm{ml}$ of defibrinated blood. The culture medium for all cell suspensions studied contained $20 \%$ of this mixture of autologous serum with methyl cellulose. The actual concentration of the serum protein corresponds therefor to $12.5 \%$ serum.

Stimulation of lymphocytes in these autologous mixed cell cultures was estimated by incubation with tritiated thymidine as in Fig. 1, and extracting the DNA, to determine the amount of incorporated radioactivity. This value is directly related to the number of cells synthesizing DNA and

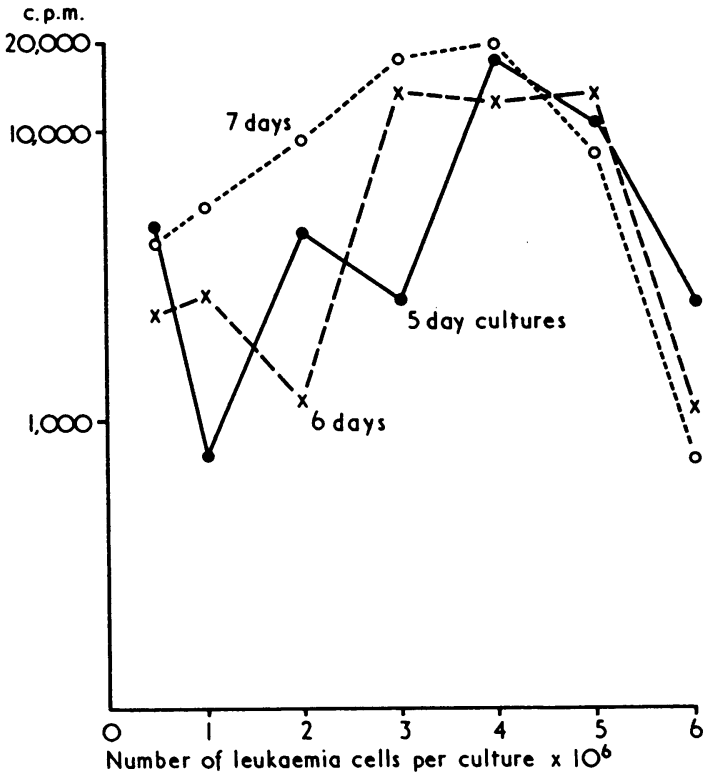

FIG. 3-Transformation in vitro of $1 \times 10^{6}$ lymphocytes by varying numbers of autologous leukaemia cells.

provides a measure of the proportion of cells that have transformed in response to the "stimulating cell." DNA synthesis in the stimulating cells (in this instance leukaemia cells) was inhibited by prior treatment with mitomycin $\mathrm{C}$ (Bach and Voynow, 1966). The volume of all cultures was $3 \mathrm{ml}$ containing a total of $1 \times 10^{6}$ "reacting lymphocytes." The stimulating cells were used in the concentration necessary to produce maximal stimulation, and, like Fridman and Kourilsky (1966), we found the optimal concentration for leukaemia cells was $4 \times 10^{6}$ cells $/ 3 \mathrm{ml}$ (Fig. 3 ).

\section{CONTROLS}

Because of the importance of ensuring on every occasion when lymphocyte transformation was being studied that each of the many variables was controlled, the following additional cultures were always included:

(a) Allogeneic Mixed Cell Reaction Using Normal Donors.Lymphocytes were obtained from a normal individual and stimulated in culture by mitomycin-inhibited allogeneic lymphocytes from another normal donor. Maximal stimulation was obtained with $0.5 \times 10^{6}$ stimulating cells $/ 3 \mathrm{ml}$ culture. This test was carried out to ensure that there were no significant day-to-day variation in culture procedure. The range of stimulation during the six-month period of the study was between 11,000 and 29,000 c.p.m. On two occasions the cells from identical twins were used and in both cases no stimulation occurred-that is, counts were less than 1,000 per minute.

(b) Cell Cultures without Stimulation.- When lymphocytes from a donor were cultured with mitomycin-treated lymphocytes from the same donor (an autologous situation) tritiated thymidine uptake was always less than 1,000 c.p.m. Similarly, stored leukaemia cells, even without mitomycin treatment, when cultured on their own for six days failed to incorporate thymidine.

(c) Allogeneic Mixed Cell Reactions Using Patients' Lymphocytes.-Patients' lymphocytes were cultured with mitomycin-inhibited normal allogeneic lymphocytes to determine variability in the recognition of foreign cells. By comparing this value with (a) above, an indication of the immune state of the patient is obtained. The magnitude of the reaction of patients' lymphocytes to autologous leukaemia cells must then be compared with these allogeneic variations. This is particularly important if allogeneic recognition is severely depressed.

(d) Storage Control.-In order to show that storage of leukaemia cells did not induce changes which caused lymphocyte stimulation, bone marrow cells were used to mimic leukaemia cells 
on some but not all occasions. Bone marrow cells were taken from patients in remission, processed in the same way as the leukaemia cells, and tested to see if they would stimulate autologous lymphocytes.

\section{AUTOIMMUNIZATION}

Stored leukaemia cells were thawed rapidly at $37^{\circ} \mathrm{C}$, washed three times with tissue culture medium 199, and resuspended in this medium at $4^{\circ} \mathrm{C}$. These cells were irradiated at $4^{\circ} \mathrm{C}$ at a concentration or $10^{8}$ cells $/ \mathrm{ml}$ with a dose of 10,000 rads using ${ }^{60} \mathrm{Co}$ gamma-irradiation at $1,500 \mathrm{r}$ per minute; they were injected within 30 minutes in all four limbs both intradermally and subcutaneously. The total number of cells injected on each occasion was approximately $1 \times 10^{9}$.

\section{Results}

Bone-marrow Controls.-A typical experiment is shown in the Table in which a patient's remission lymphocytes were

Counts per Minute in Separate Experiments When Remission Lymphocytes from One Patient were Stimulated by Different Mitomycin-treated Cells

Stimulating Cells

Allogeneic normal lymphocytes .

Autologous marrow cells frozen and thawed

Autologous leukaemia cells frozen and thawed...

Autologous remission lymphocytes (negative control) .

greatly stimulated by autologous leukaemia cells but failed to be stimulated by autologous mitomycin-treated bone-marrow cells. Both the bone-marrow cells and the leukaemia cells had been exposed to an identical storage procedure, showing that the stimulation induced in the remission lymphocytes cannot be due to changes produced by the freezing procedure. Similar experiments with remission lymphocytes that had been frozen and thawed instead of bone-marrow cells also failed to cause any stimulation.

Leukaemia Cell Recognition.-Stimulation of remission lymphocytes by stored autologous leukaemia cells occurred in all nine patients studied, but this response was variable, as was the capacity to recognize allogeneic cells (Fig. 4). As previously described, the allogeneic mixed cell reaction between lymphocytes of normal individuals produced a range of values in counts per minute between 11,000 and 29,000 , but stimulation of patients' remission lymphocytes by allogeneic normal lymphocytes was found to have much wider variation, with many reactions severely depressed. Because of this it was meaningful only if stimulation of patients' remission lymphocytes by autologous leukaemia cells was expressed relative to the extent of transformation induced by allogeneic lymphocytes. Of the many occasions that the nine patients were studied, in only five instances did lymphocytes fail to be stimulated by autologous leukaemia cells (Fig. 4), and this was always associated with impairment of allogeneic recognition. At some time the lymphocytes from every patient were capable of being stimulated by autologous leukaemia cells, and often this occurred to a degree equal to the stimulation produced by allogeneic cells tested at the same time.

Effect of Immunization with Irradiated Autologous Leukaemia Cells.-Seven patients were autoimmunized and two were immunized twice. On all nine occasions there was an increased stimulation of the patients' lymphocytes by autologous leukaemia cells following autoimmunization (Fig. 5).

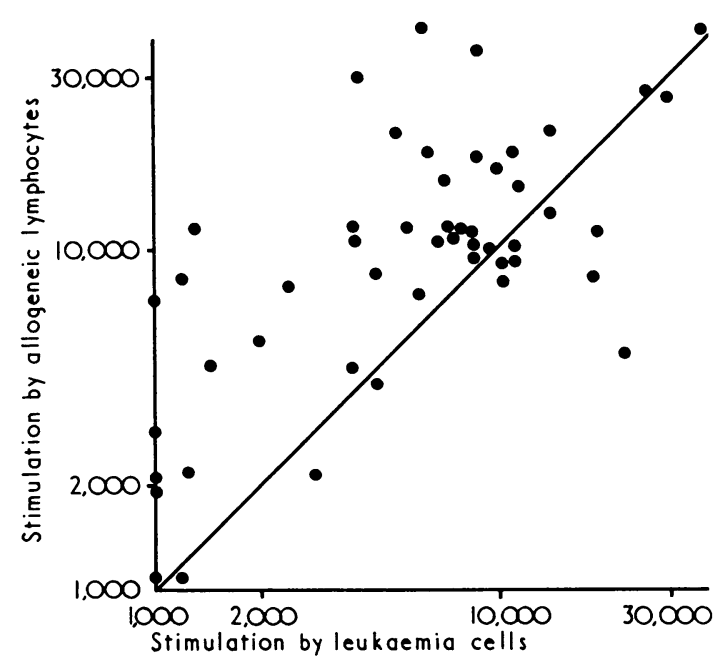

FIG. 4-Stimulation in counts per minute when remission lymphocytes from nine patients were stimulated by normal allogeneic cells (vertical axis) and by autologous leukaemia cells (horizontal axis). Each point represents one complete experiment when the lymphocytes were tested against both of these stimulating cells separately. If patients' lymphocytes recognized allogeneic lymphocytes and their own leukaemia cells equally well then all points would lie on the transverse line drawn. Any point to the right of the line means the leukaemia cells are recognized as foreign better than allogeneic cells. On only five occasions were the counts below 1,000 per minute when the lymphocytes were stimulated by leukaemia cells-that is, at the upper end of the negative control level. In these instances where there was no stimulation by the leukaemia cells there was also poor stimulation by allogeneic cells.

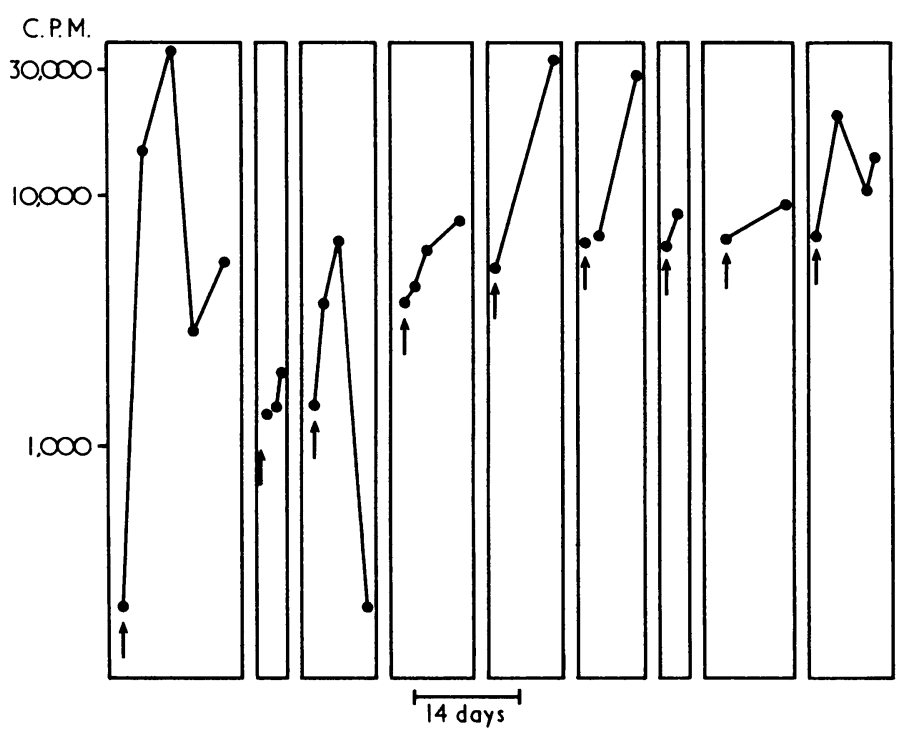

FIG. 5-Changes in counts per minute when remission lymphocytes were Seven patients were autoimmunized and two were immunized twice. The arrows indicate the time of immunization.

In all instances this occurred within a few days, but in some cases it was transitory. Autoimmunization also affected the capacity of the patients' lymphocytes to respond to normal allogeneic cells (Fig. 6); those cases where allogeneic stimulation was below the normal range of 11,000 c.p.m. before autoimmunization showed an increase in their response. In these cases, however, autoimmunization increased lymphocyte "recognition" of leukaemia cells to a greater extent than "recognition" of allogeneic cells. This is shown in Fig. 7, and indicates that there was both a specific and a non-specific effect of autoimmunization on patients' lymphocytes. On no occasion was there any indication of an immunological skin reaction at the site of the intradermal injections. 


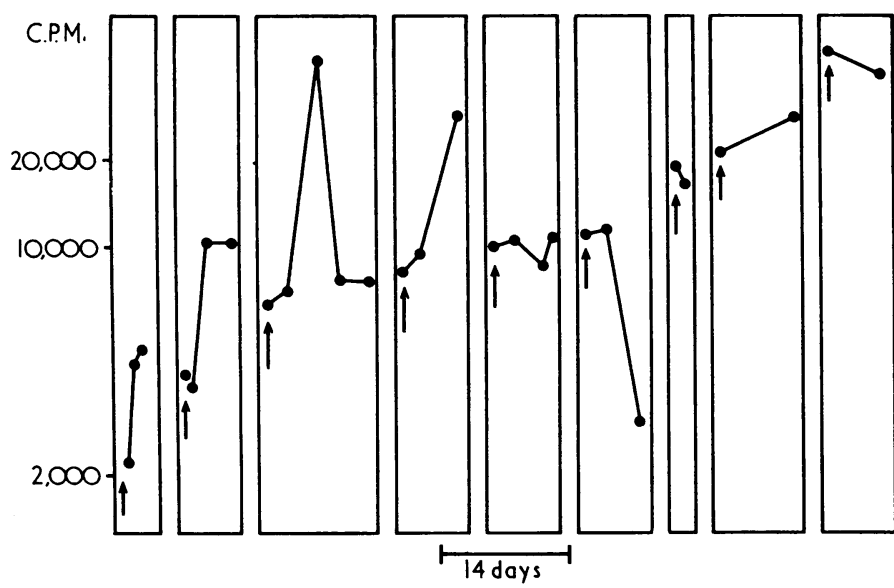

FIG. 6-Changes in counts per minute when remission lymphocytes were stimulated by allogeneic cells under the same circumstances as in Fig. 5 .

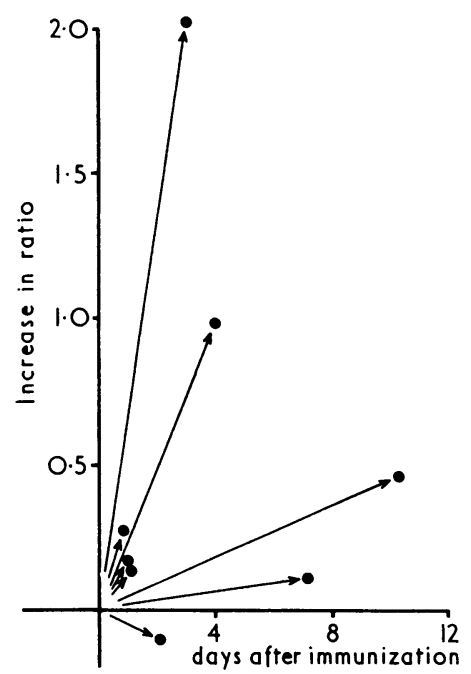

FIG. 7-Increase in the ratio between the ability of the remission lymphocytes to recognize leukaemia cells and normal allogeneic lymphocytes after autoimmunization in eight patients studied.

\section{Discussion}

Mixed cell culture techniques used in our laboratory have confirmed the findings of Viza et al. (1969) and Fridman and Kourilsky (1969) that the remission lymphocytes of patients with acute leukaemia react in culture to their own stored leukaemia cells as if these cells carried a foreign antigen. We have further been able to show that this response is much stronger than previously thought, and is not due to an artefact produced by storage of the leukaemia cells. Because of interference by transplantation antigens it is not possible by this procedure to determine whether the antigen(s) in human acute leukaemia is individually specific as in chemicallyinduced experimental animal tumours or "group" specific like the neoantigens of virally induced tumours. The finding that after autoimmunization the extent of stimulation of lymphocytes by leukaemia cells increased suggests that the immunizing procedure had increased the proportion of lymphocytes capable of responding to the leukaemia cells. It must be pointed out here that there is an alternativenamely, that autoimmunization changed the serum of the patient in such a way that lymphocyte stimulation was more effective. In all the cultures reported here the cells were cultured in medium containing $20 \%$ of the patients' serum taken at the same time as the reacting lymphocytes.

Attempts to prolong remission in patients with acute leukaemia by immunological procedures (Mathé, 1969) make it of the greatest importance to measure changes occurring in patients after the injection of irradiated autologous leukaemia cells when in remission. This test appears to provide such information and could be further used in patients after immunization with allogeneic leukaemia cells, B.C.G., or Corynebacterium parvum. In this way it may be possible to develop a rationale for deciding on the optimum dosage and schedule for future trials of immunotherapy, and so determine if there is a place for this form of treatment in the long-term control of acute leukaemia.

This work has been supported by grants made to the Chester Beattv Research Institute by the Medical Research Council and the Cancer Research Campaign, and a special grant from the Frazer Trust.

We would like to thank Sir Ronald Bodlev-Scott, Dr. P. E. Thompson Hancock, Dr. H. Kay, Dr. D. Lawson, Dr. John Matthias, and Dr. Derek Crowther for their interest in and support of this work.

\section{References}

Bach, F. H., and Voynow, N. K. (1966). Science, 153, 3735.

Bain, B. (1970). Clinical and Experimental Immunology, 6, 255.

Buckner, D., Graw, R. G., Eisel, R. J., Henderson, E. S., and Perry, S. (1969). Blood, 33, 353.

Coulson, A. S., and Chalmers, D. G. (1967). Immunology, 12, 417.

Crowther, D., et al. (1970). British Medical fournal, 4, 513.

Fridman, W. H., and Kourilsky, F. M. (1969). Nature, 224, 277.

Mathé, G., et al. (1967). Cancer Research, 27, 2542.

Mathé, G., et al. (1967). Cancer Research, 27, 25

Parr, I. (1971). Proceedings of the 4th Conference on Cancer Immunity Polerance Oncogenesis. Perugia University, Perugia, Italy. In press.

Viza, D. C., Bernard-Degani, O., Bernard, C., and Harris, R. (1969). Lancet, 2, 493. 